\title{
The pragmatics of profiling: Framing effects in text interpretation and text production
}

\author{
Bregje C. Holleman *, Henk L.W. Pander Maat \\ Utrecht Institute for Linguistics OTS, Utrecht University, Trans 2-4, 3512 JK Utrecht, The Netherlands \\ Received 15 January 2008; received in revised form 11 May 2008; accepted 21 September 2008
}

\begin{abstract}
When describing sets or entities in terms of a two-valued variable, one may choose either value to do the job. For instance, the success of a medical treatment may be described in terms of its survival rate (i.e. in a positive frame) or in terms of its mortality rate (the negative frame). Psychological studies have shown that the frame, or profile as we prefer to call it, influences the evaluations of readers: positively profiled objects are evaluated more positively than negatively profiled ones. This article analyzes the communicative mechanisms behind profile production and interpretation. It suggests two pragmatic inference rules to be at work: a heuristic called Argumentative Orientation, and a Manner implicature based on markedness differences.

Data from six experiments with discourse completion tasks show consistent effects of Argumentative Orientation and Markedness. Argumentative Orientation accounts for the tendency for speakers to choose the profile in line with the conclusion one wants to draw and for hearers to interpret the profile accordingly. The strength of the implicated Argumentative Orientation is further modified by markedness inferences, stemming from whether the marked or unmarked profile for this particular pair and context is chosen. A socalled Marked Skewness effect produces a stronger Argumentative Orientation for the marked member of the opposition.
\end{abstract}

(C) 2008 Elsevier B.V. All rights reserved.

Keywords: Framing effects; Markedness; Profile-base configuration; Argumentative Orientation; Conversational implicature; Antonymy

\section{Introduction}

"Suppose you're organizing a dinner party, and making lasagne. How would you rate ground beef which is $25 \%$ fat (condition 1) or $75 \%$ lean (condition 2). Please rate the beef on a scale from fat-lean, greasy-greaseless, high qualitylow quality and good tasting-bad tasting".

This scenario is an example of attribute framing, loosely based on Levin and Gaeth, 1988. An object (ground beef) is described in two different ways (the proportion of leanness vs. the proportion of fatness). Half of the subjects are asked to evaluate the beef described in a positive way (proportion of leanness), whereas the other half evaluate the beef that was framed negatively (percentage of fat).

When we use verbal information to evaluate objects or events or to make decisions, we are very likely to be influenced by the frame of the information. A course described in terms of its success rate will be evaluated more positively than a course described in terms of its fail rates, despite the fact the content of the information is truthconditionally equivalent. That is the type of phenomenon the research reported here aims to explain. This type of framing is called attribute framing. In this type of framing an object or event is either described in positive terms (e.g.

\footnotetext{
* Corresponding author.

E-mail address: Bregje.Holleman@1et.uu.nl (B.C. Holleman).
} 
survival rate) or in equivalent negative terms (e.g. mortality rate). The dependent variable is the evaluation of the object or event in terms of likeability or some other type of gradable evaluation. Generally, a 'valence consistent shift' is found: if an object or event is described in positive terms, it is likely to be evaluated more positively compared to the same object described in equivalent negative terms. ${ }^{1}$

Several word pairs are used (and re-used) in attribute framing research (see Levin et al., 1998 for an overview). These word pairs include: the percentage leanness or fatness of consumer products; the percentage success rate or failure rate of programs, teams, et cetera; and the mortality or survival rate of medical treatments. Games are framed in terms of shots made versus shots missed, exams in terms of answers correct versus answers incorrect, gambles in terms of their probability of winning or of losing. By and large a valence consistent shift is found in attribute framing experiments, regardless of the task.

As Levin et al. (1998) have given a thorough overview of previous research into attribute framing, we will not repeat that here. It is useful, however, to have a closer look at the tasks in the experiments. Most experiments into attribute framing use the same tasks, and the same (types of) word pairs to frame their scenarios. The task is usually to evaluate an object or program that is described in a little scenario on a scale from bad-good, negative-positive, acceptableunacceptable. Also scales rating the taste or the healthiness are used (e.g. Levin and Gaeth, 1988; Sanford et al., 2002). Sometimes yes/no-judgments are asked ('Would you be in favor of the program?', or 'Is this a good thing?'). Only sporadically, a behavioral intention is elicited, e.g. the willingness to allocate funds, or the amount of money one would be willing to spend on the product (e.g. Levin et al., 2002).

Sometimes, no evaluation of the product is asked, nor an intention concerning the product, but a discourse completion task is given. This discourse completion task can either be designed to have subjects interpret a frame, or to have them produce a frame. In an interpretation task, the frame is given ('This beef contains $5 \%$ fat'). Subjects choose between alternative sentences to complete the scenario (e.g. 'It is widely believed to be a healthy/unhealthy product'). In a frame production task an evaluation is given ('This beef is widely believed to be a healthy product') and subjects have to choose between alternative frames to follow ('The beef contains $5 \%$ fat', vs. 'The beef is $95 \%$ fat free'). ${ }^{2}$ Discourse completion tasks are not generally used in attribute framing research. Sher and McKenzie (2006) use a discourse completion task of frame production, Sanford et al. (2002) use a discourse completion task of frame interpretation.

This article proposes a linguistic explanation of attribute framing effects. We start with a discussion of possible causes of attribute framing effects. Existing explanations focus on cognitive mechanisms that cause the valence consistent shift in framing effects. We argue that these theories cannot fully explain framing effects and propose instead a pragmatic perspective: we describe the communicative mechanisms of frame production and frame interpretation, in which not only valence consistent shifts play a role, but other tendencies too, such as markedness. We propose a heuristic of Argumentative Orientation to understand attribute framing effects, or, as we prefer to call them: profiling effectsbecause it is the profiled, highlighted part of the semantic 'picture' that is varied. In addition, we discuss how contrasts are not always symmetrical. In most scenarios, one of the options is the normal, or unmarked one, and choosing the marked option may lead to additional inferences. Next, we present a number of experiments in which the effects of Argumentative Orientation and Markedness are tested. We use a variety of scenarios in order to be able to assess the generality of these implicatures. In the discussion, the results are related to previous attribute framing research.

\section{Towards a communicative explanation of framing effects}

Why is ground beef that is $25 \%$ fat judged to be less tasty than beef that is described to be $75 \%$ lean? Levin et al. (1998) discuss various explanations. One is that the positive label (lean) is connected with positive associations, whereas the negative ( fat) is connected with negative ones. This would explain why Levin and Gaeth (1988) not only found a profile effect on whether subjects evaluated the beef to be fat/lean, but also on associated dimensions such as taste and quality. So the profile possibly affects the representation and encoding in associative memory, and this in turn

\footnotetext{
${ }^{1}$ In an exhaustive meta-analysis of framing research, Levin et al. (1998) give an overview of past research and distinguish between different kinds of framing. Attribute framing should not be confused with the other types of framing they distinguish: risky choice framing and goal framing. In risky choice framing (Tversky and Kahneman, 1981) subjects evaluate a programme differently depending of the frame (positive/negative) and depending of the extent to which the outcomes are certain: they have to choose between a risky (possible outcome) and a riskless option (certain outcome). In goal framing, both options are equally certain or risky, but the goals or consequences of a behaviour are either framed negatively (avoiding a negative consequence) or positively (focusing on the positive goal that can be obtained).

${ }^{2}$ These examples are based on Sanford et al. (2002). They only use frame interpretation tasks, no production tasks.
} 
may lead to a confirmation bias and selective attention when retrieving or forming a judgment. Due to a valenced encoding in memory, subjects tend to attend differently to the positive or negative aspects of the required evaluation dimension, thus effectively changing subjective scale values (Levin et al., 1998:164) and subsequent responses. This interpretation is in line with the concept of priming: a positive label can prime a positive evaluation. In the standard priming paradigm, a prime that is not related to the target (i.e. 'cockroach' to 'Bush' vs. 'sunshine' to 'Bush') is shown to affect the evaluation of the target ('Bush'). In framing research, the profile is related to the target, which may further increase the size of the priming effect (Levin et al., 1998).

These explanations are interesting but still rather unsatisfactory, mainly because they do not make clear why and how the associations attached to a profile so strongly affect readers' evaluations or discourse completions. It is as if associations are activated rather mechanically and no readers' expectations or inferences are involved. Results of discourse completion tasks show that such inferences do arise. In order to explain these results, a more communicative point of view seems to be called for. Sher and McKenzie (2006) use such a point of view, by reasoning from what they refer to as information leakage. In this section, we first discuss their idea of information leakage in attribute framing and proceed by proposing a modified framework.

Attribute framing research assumes that the positive and negative frames are logically equivalent, ${ }^{3}$ and therefore should lead to similar evaluations or completions. Sher and McKenzie question this equivalence and hypothesize that frames 'leak information'. In describing a fixed state of proportionate affairs, speakers (or writers) are more likely to describe the proportion in terms of X1 when X1 has increased relative to the reference point proportion (the norm, a previous state, or an expectation) than when X1 has decreased relative to this reference point (RP). Listeners (or readers) are sensitive to this mechanism and infer the speaker's reference point from the speaker's frame. So, if a speaker describes a glass to be half full, he generally does this when the glass was less full previously. Listeners, in turn, infer that the glass was less full previously, or that the glass is now fuller than was to be expected.

The use of a given frame signals to the listener that the proportion used in the frame has increased relative to a reference point. And "[s]ince it is generally good to have more of a good thing, and bad to have more of a bad thing, the reference point hypothesis predicts that proportions couched in terms of good things will lead to more favourable evaluations than proportions couched in terms of bad things [...so] valenced frames will (and sometimes should [stress by S\&McK]) produce valence-consistent shifts" (Sher and McKenzie, 2006:16).

This explanation is interesting because of its two-sidedness: speakers use implicit reference points in the production of frames, and listeners infer from the fact that a speaker chooses frame X1 over frame X2 that he endorses a point of view consistent with the property profiled.

Still, the explanation put forward by Sher and McKenzie is not really communicative, as it does not include any reference to the communicators' intentions. The central metaphor of leakage suggests an automatic process, beyond the control of the language user. In order to present a truly reflexive account, we need rules or inferences to bridge the gap between psychological states and linguistic choices.

\subsection{A pragmalinguistic view on framing contrasts}

For a linguistic perspective on the lexical contrasts used in framing research, we concentrate on the difference between half full and half empty. This focus is mainly for expository reasons, but also this contrast is quite representative of the contrasts used in attribute framing research. An example of an attribute framing experiment with discourse completion would be: "The last couple of years, I bought few/many new clothes. My closet is now half full/ half empty". Or in an evaluation task: "Tony needs some time to do odd jobs about the house. For next month, his diary is half full/half empty. Is this a good thing? Yes/No".

Let us start with an important observation in Langacker (2000:28). He says that full and empty assume different baselines: "Half full assumes the baseline of the glass being empty and assesses how far the situation diverges therefrom in the direction of it being full, whereas half empty does the opposite". The full/empty-contrast is a type of construal that varies "the background against which we conceive of the situation described". Langacker assumes a 'zero degree' of a property as the baseline for descriptions in terms of this property. This means that when a property is ascribed, this description is oriented 'upward', that is, it focuses on the upward deviation from the baseline. Note that this is different from Sher and McKenzie's (2006) claim that the property in question has increased, or is abundantly

\footnotetext{
${ }^{3}$ Linguists may prefer the term 'truth-conditionally equivalent', instead of 'logical' equivalence.
} 
present. The degree of the property is not decisive; conveying its presence itself is already positively oriented since it represents it as being more than zero.

There is another notion of Langacker's that is central to understanding the full/empty-contrast: the distinction between profile and base (see Croft and Cruse, 2004:14-24 for an introductory discussion). Every linguistic expression profiles a certain region in our conceptualization of a phenomenon, while other regions remain in the background. For instance, in elbow a certain part of the arm is profiled, while the rest of the arm is the base in this conceptualization. Some expressions differ not in their profiles but in their bases. For instance, both coast and shore profile the strip of land adjacent to the sea; but coast assumes the land as the base, while in shore the profile is seen from sea, so to speak. The interesting thing about half full and half empty, and all other two-sided contrasts that can be used in attribute framing, is that both profile and base are affected. In fact, the entire profile-base configuration is turned upside down: halffull profiles the filled region of some container object, leaving the empty region in the background as the base; half empty works the other way round.

\subsubsection{Argumentative Orientation}

So far, we approached framing contrasts from a cognitive semantic perspective. To explain how profile choices and intended conclusions are to be related by hearer inferences, we need to adopt a pragmatic stance. A pragmaticist would probably start by noting that full and empty belong in different scales or gradations. In neo-Gricean pragmatics (Horn, 1989; Levinson, 2000), scales are used to account for Quantity-based implicatures. For instance, there is a scale <all, some $>$, meaning that the stronger term all entails the weaker term some. The standard Q-implicature is that uttering the weaker term implicates that the stronger term does not apply, so that some implicates not all. All and some belong to the positive quantifier scale; but there is also a negative scale, including <none, few $>$. This scale explains the implicature from few to not none.

Scales may also be constructed for gradable adjectives. So there is a positive scale containing strings like $<$ boiling, hot, warm $>$ and a negative one with $<$ freezing, cold, cool $>$. Negation reverses a scale. Hence we find a scale such as $<$ not warm, not hot, not boiling $>$ : this means that not warm is the strongest statement since it excludes the largest area (Horn, 1989).

The position of full and empty in this domain is somewhat unclear. Their scales differ from the classical pragmatic scales in that there are no lexical alternatives indicating different scale positions. We will need degree words or numerals to form these scales: <entirely full/empty, half full/empty $>,<100 \%$ full/empty, $75 \%$ full/empty, 50\% full/ empty, ... > . But numeric scales like <entirely, half $>$ and $<100 \%, 75 \%>$ differ from lexical ones. It is a matter of controversy whether they are really pragmatic scales like the quantifier scales (Bultinck, 2005).

But while full and empty do not belong to classical pragmatic scales, they clearly differ in their 'orientation'. Horn (1989:242) suggests this by noting that full and empty display a particular kind of scale reversal: a glass not halfempty seems to be fuller than a glass not halffull. This is because not can be read as less than here. This observation ties in nicely with both Langacker's remark on the different baselines and orientations of the two terms and with Paradis and Willners' (2005) empirical analysis of full and empty. They characterize empty and full to be basically bounded antonyms, therefore contradictories and not scalar. That is, full-empty is more like dead-alive than like long-short. Empty is especially strongly non-scalar, according to judgments of language users collected by Paradis and Willners. However, if the antonymic relation is foregrounded or if the terms are negated, these bounded antonyms display a scalar behavior. Paradis and Willners show that the behavior of full-empty is very peculiar in this respect. For most antonyms, the interpretations are ordered as follows: $\mathrm{x}$ (e.g. long) $>$ not $\mathrm{y}($ not short $)>\operatorname{not} \mathrm{x}$ (not long) $>\mathrm{y}($ short $)$. However, for full-empty the order is $\mathrm{x}($ full $)$-not $\mathrm{x}$ (notfull)-noty (not empty)-y (empty). In order to use $\mathrm{x}$ ( full) ory (empty), something has to be completely full or completely empty. If the endpoint is not reached, not $x$ or not $y$ is to be used. This interpretation of not as not completely or almost supports the claim that full and empty have an 'upward' orientation, that is, an orientation towards filling or emptying.

So there is a sense of 'upward direction' in both full and empty, and these two directions are in direct opposition. Furthermore, the 'positive-negative' difference between full and empty seems comparable to that between warm and cold, and between a few and few. However, Horn and Levinson do not say very much about the meaning of this difference. This is where the French linguist Oswald Ducrot comes in. He claimed (Ducrot, 1973, 1980; see Pander Maat, 2006) that the difference is one of argumentative orientation, meaning that contrasting conclusions can be drawn from the two items. For instance, in a situation in which it is warm can be used to argue for making a walk, it is cold can be used to argue against it. And while a few can be used to argue that some phenomenon exists and needs to be reckoned with, few can be used to argue that its frequency is non-significant. 
Table 1

Diagnostics for classes of implicatures (Levinson, 2000:41), with a column added for the Argumentative Orientation implicature.

\begin{tabular}{lllll}
\hline PROPERTIES & CLASSES & & & \\
\cline { 2 - 5 } & Quantity & Manner & Informativeness & Argumentative Orientation \\
\hline Negative inference & Yes & Yes & No & No \\
Inference to the stereotype & No & No & Yes & No \\
Metalinguistic basis & Yes & Yes & No & Yes \\
\hline
\end{tabular}

Some might argue that these Argumentative Orientations are part of the semantics of expressions rather than pragmatic inferences made on the basis of the semantic content. However, we do not expect one-to-one correspondences between profiles and conclusions, but only probabilistic patterns of 'argumentative coherence': profiling choices will partly, but not fully determine the conclusions to be drawn from an utterance. Hence we regard these orientations as defeasible inferences, just like other pragmatic inferences. Besides, Argumentative Orientations may differ in strength for marked and unmarked members of an opposition, as is discussed below.

How should we place this Argumentative Orientation in terms of the classifications of implicatures proposed by Horn (1989) and Levinson (2000)? Recall that both authors mention Quantity (Q) implicatures, based on scales of the type we just discussed. Horn only adds Relation (R) implicatures, Levinson Manner (M) and Informativeness (I) implicatures. We use Levinson's more detailed classification. His M-implicatures (probably classified as R by Horn) go by the rule "What's said in an abnormal manner isn't normal", and capture all kinds of suggestions produced by unusual and less economic ways of saying things (e.g. cause to die is heard as referring to a non-standard way of killing). Informativeness implicatures refer to the tendency to construct maximally informative, often stereotypical interpretations (e.g. a road is taken to refer to the standard hard-surface type of road, as long as no information to the contrary is provided).

Levinson (2000:41) provides a list of diagnostics for classes of implicatures. Let us examine the behavior of Argumentative Orientation implicatures with regard to the diagnostics (see Table 1). While Q-implicatures and Mimplicatures are essentially negative inferences because they implicate that a particular interpretation is not intended by the avoidance of the corresponding stronger or simpler expression, I-implicatures and A-implicatures lack this property. But A-implicatures differ from I-implicatures since Argumentative Orientations cannot be said to be enrichments of the simplest type of expressions, as they affect both pair members. What A-implicatures share with Qinferences and M-inferences is their metalinguistic basis: they rely on contrasts between pairs of linguistic forms. They are most similar to the M-type in that both $\mathrm{A}$ and $\mathrm{M}$ rely on pairs of synonymous forms.

We do not pretend to have uncovered a new class of implicatures here; the exact place of argumentative implicatures remains a topic for further study. For now it suffices to say that argumentative implicatures rely on paradigmatic oppositions like Q- and M-inferences, but lack the characteristic of negative inference. Moreover, they seem to behave in a 'generalized' way, in the sense that their operation does not in itself require lots of contextual information; but in the end, this is an empirical issue of course.

We further speak of Argumentative Orientation-inferences (AO). The general heuristic underlying AO-inferences is described below. First, we discuss what kinds of utterances allow these inferences. So far we have used half full/half empty as our example. But more generally, framing contrasts may occur when talking about two kinds of situations:

i. Entities that are incrementally involved in some process; part of the entity has gone through the process, while the other part has not. The process may be one of consumption (glasses half full/half empty), production (half of the book is already written/yet to be written), or change of shape, place or state (half of x is visible/invisible, painted/ yet to be painted, clean/dirty). ${ }^{4}$

ii. Sets that can be split into two parts by means of a binary variable for which values are lexicalized to the same degree, such as percentage lean vs. fat, half of $S$ is better than $x$ vs. half of $S$ is worse than $x$, failure rate vs. success rate, or percentages men/women.

\footnotetext{
${ }^{4}$ This analysis is partly based on Kennedy and McNally (2005:363), who provide a list of examples of adjectives that combine with proportional modifiers and the situations or scenarios that are compatible. They list 'classic' incremental theme arguments (e.g. half eaten cookies, a partially written novel), Pat $_{+-}$arguments (e.g. fully straightened teeth, partially frozen liquid) and Pat $_{\text {LOC }}$ arguments (e.g. a partially crossed desert, or fully raised blinds). See also Teigen and Karevold (2005) who demonstrated AO effects for these specific types of contrasts.
} 
Both environments have a two-valued variable that exhaustively characterizes an entity or set. In such cases, only one value needs to be used to describe the entire object; this creates the option of choosing either profile. As the psychological framing literature shows, this is a considerable set of cases.

We now return to our problem of explaining the AO-inferences to be drawn from profiled utterances. We propose the following heuristic to account for Argumentative Orientation implicatures:

Speaker's maxim: when a situation lends itself to description in terms of a two-valued variable, profile the component carrying the value that best fits the direction of the conclusions one would prefer to be drawn from the utterance.

Recipient's corollary: when a situation lends itself to description in terms of a two-valued variable, the component that is profiled indicates the direction of the conclusions the speaker would prefer to be drawn from the utterance.

The AO-notion is better equipped to explain attribute framing effects than the explanation of information leakage. With the AO-notion, if a speaker utters (1), it is not necessary for the hearer (1) to infer that this is 'full' compared to some reference point and (2) to infer that this abundance of fullness is positive and (3) to draw a positive conclusion about the situation. Instead, the hearer can (1) understand that there is a degree of fullness and (2) infer that the speaker profiles this degree because it fits the direction of the conclusion he wants to be drawn: this will be a conclusion based upon the presence, not the absence of wine in the glass.

\section{(1) The glass of wine is half full.}

We note in passing that these two assumptions may have persuasive effects in evaluation tasks. When the message is processed in a shallow way (called 'heuristic' or peripheral' processing by persuasion theorists, e.g. Petty and Cacioppo, 1986) the hearer may go along with the implicated conclusion without questioning it. This seems to be Sher and McKenzie's line of reasoning in their explanation of valence-consistent shifts. This persuasive effect, however, is not the focus of the present study.

\subsubsection{Manner implicatures deriving from markedness asymmetries}

AO-inferences are not the only forces determining frame interpretations. The profile's orientation provides a cue to the probable direction of the conclusion to be drawn. But this cue may be stronger or weaker according to whether this profile is unmarked or marked in a given scenario or context. In order to describe the production and interpretation of profiles fully, these differences in markedness should be taken into account.

As is well known, linguistic oppositions are only rarely symmetric. One member of the pair is generally the usual or 'unmarked' member, whereas the other is more unusual and 'marked'. This markedness can be explicit, through a prefix such as in- or un- or a suffix such as -less, but it can also be semantic. For example in pairs of lexical items in which one expresses a semantic component that is left unexpressed by the other (e.g. bitch vs. dog), the less specific word $(\operatorname{dog})$ is unmarked whereas the more specific word (bitch) is marked (Comrie, 1996:5).

A major issue with markedness in the literature is whether or not it is a valid notion (Comrie, 1996:1), and whether it should be replaced with notions such as frequency asymmetry, structural asymmetry, or pragmatic inferences (Haspelmath, 2006). We do not intend to take position in that discussion, but merely use the term markedness to describe the situation in which a particular feature has two values and one of these values is more frequent, and used in a wider variety of contexts than the other (Comrie, 1996:1).

We expect that markedness differences will probably be pragmatically exploited. Here the logic of Levinson's $\mathrm{M}$ (anner)-heuristic is important, although it should be broadened a bit. Levinson's heuristic distinguishes between normal and simple ways of saying things, such as kill, and less economical, often periphrastic ways of saying things such as cause to die. The extra processing effort required by the marked phrasing needs to be rewarded by an informational surplus. Hence, unusual phrasings lead to extra inferences based on the assumption that the speaker would not have used the unusual profile if he did not want those inferences to be drawn.

Now, what is the unmarked profile in a particular utterance context? Several factors have been suggested to help predict marked and unmarked pair members. Givón (1995:63-66) claims that perceptually or culturally salient pair members tend to be unmarked. Perceptive saliency explains the asymmetry in pairs such as big-small and near-far. Another consequence of this saliency is that positive expressions tend to be unmarked: non-events and non-states can 
be perceived and conceptualized less easily. This polarity asymmetry, when applied to the full-empty contrast, identifies full as the unmarked and empty as the marked member. This seems to be supported by the fact that full tends to precede empty when the two terms are listed, and by the use of full in neutralized contexts such as how $X$ is it?

Givón also mentions cultural saliency as a determinant of markedness, but here our intuitions are more mixed. For instance, while male seems the unmarked term in the male-female opposition, there are contexts in which we expect the number of women to be profiled, not the number of men. For example, if a population is described in which typically, or culturally, more men than women are expected, i.e. in a school for motor mechanics, it seems unmarked to describe the population in terms of the proportion of women-because this smaller proportion is already expected, or because even the small proportion is more than expected for this population.

We would like to add to that that the unmarked profile may also depend on the scenario that is being described. Often, markedness depends on the direction or goal of the process the entity is engaged in: a process is preferably described in terms of what has been completed or has been done, not in terms of what still needs to be done. For a filling process this would lead to full as the unmarked term, while for an emptying process empty seems the term to use.

In our hypotheses, we initially follow polarity as the determiner of markedness: the positive pair member will be generally unmarked.

An important semantic consequence of markedness is that the marked term has a more restricted interpretation than the unmarked one. For instance, the How long is it? can be answered both with short and long, whereas How short is it? seems to presuppose that it cannot be long (e.g. Givón, 1995; Murphy, 2003). Likewise in X is better than Y, X may be good or bad; whereas in $X$ is worse than $Y$, X must be bad and cannot be good (Murphy, 2003:185).

The intuition that the marked term has a more restricted interpretation has not yet been applied to profile contrasts of the kind used in framing research. The difference is fairly evident for pairs like dog-bitch and long-short, for which it manifests itself in the denotations and the grammatical distribution of the pair members. It is theoretically important to examine this difference in pairs like half full-half empty and even 50\% survive-50\% die, which are far more symmetrical from a grammatical and semantic point of view. Possibly, the markedness concept is relevant to a larger class of contrasts than it has been applied to so far.

Our analysis of markedness effects proceeds by identifying unmarked and marked terms on the basis of the direction of the scenario and on the basis of the positive or negative polarity of the item. For cases with a clear markedness contrast, our hypothesis is that the unmarked profile will show a more even distribution over the opposing conclusions than the marked one, which will be more confined to a single conclusion. This seems to be the most straightforward interpretation of the general expectation of marked terms to have more restricted meanings than unmarked terms.

\subsubsection{Hypotheses and outline of the experiments}

In sum, the direction of the utterance's Argumentative Orientation primarily depends on the profile choice, and its strength is affected by the markedness of this profile. In the remainder of this article, we present data from a number of experiments investigating the AO-inferences and M-inferences. We do so for a broad range of word pairs in attribute framing scenarios. We use discourse completion tasks with frame production tasks, as well as some frame interpretation tasks. The methods and designs of the experiments are described in the next section, and section 4 discusses the results. But before we move on to the results section, we now illustrate the kind of predictions that we make regarding Argumentative Orientation and Markedness, and the ways they have been tested.

Consider (2), which is production item 2 from the first experiment (see Appendix A.1):

(2) Choose the sentence that best fits next.

Next week I'll have much/little time to come over and help you with odd jobs about the house.

(A) My diary is half full; (B) My diary is half empty.

In this item, a conclusion is given (I have a lot of time vs. I have little time), and subjects have to choose a frame (halffull vs. half empty) to continue the scenario. AO predicts that subjects will more often choose the halffull-profile as a continuation to the little time-conclusion than they will for the lot of time-conclusion. The unmarked option in this scenario is halffull, as diaries tend to fill (goal directedness), and as full can be used in neutralized contexts (compare How full is your diary? and How empty is your diary?). A second hypothesis follows the markedness asymmetry: we expect the unmarked option to be more evenly distributed over the two conclusions, and the marked option to be 
more skewed in the direction of the corresponding conclusion; option A ( $h$ alffull) can be a continuation in a lot of time as well as to the standpoint of little time, whereas option B (half empty) will be chosen predominantly in the lot of time-context. We refer to this as a Marked Skewness effect (MS-effect).

In frame interpretation items, the hypotheses work a little bit differently. As an example, consider the interpretation item in (3) (item 1 in Appendix B):

\section{Choose the sentence that best fits next.}

My diary is half full/half empty.

(A) So I will have quite a lot of time to come do odd jobs about your house.

(B) So I will have little time to come do odd jobs about your house.

In this item, the profile is given (a half full vs. a half empty diary) and subjects have to choose a continuation. This continuation is a conclusion to be drawn from the situation described in the first utterance. AO predicts that in the situation of a half full diary subjects will more often choose the little time-continuation than they will for the half empty diary. Markedness, however, modifies this prediction as there is a difference in markedness between half full and half empty. The marked profile half empty is expected to lead to more pronounced AO-inferences than the unmarked half full. Hence, we predict that the continuation preferences for halffull will be more evenly distributed over the options A and B than those for half empty. This is a Marked Skewness effect.

\section{Description of the experiments}

We conducted six experiments. The majority of the experimental items focus on the pair half full vs. half empty, similar to the work by Sher and McKenzie (2006). A large variety of scenarios is used with this word pair. A number of other word pairs are included in order to be able to generalize to attribute framing in general. Previous research has already shown the two-sidedness of the heuristics underlying framing effects in frame interpretation as well as frame production tasks. In our experiments, we mainly focus on frame production and thus only included a few interpretation items.

The first two experiments were conducted by the authors of this article. The other experiments were carried out for students' BA theses, under close supervision of the authors. All experiments were paper-and-pen experiments with discourse completion tasks in Dutch. Subjects received a number of little scenarios, which they were asked to complete. Most experiments consisted of production items only, whereas some had a mix of interpretation items and production items. In each experiment, Argumentative Orientation was not the only heuristic being tested. Items testing other principles underlying framing effects are viewed as filler items and were excluded from the analysis for this article. The number and types of subjects also varied between experiments (Table 2).

Typically, the experiments started with the instruction "In this research we are asking you to finish or interpret little texts. You are asked to pick one of two options. Please choose the option that you find most logical on first sight, or that you think sounds best. Please follow your intuitions and do not think long about it. It will take about 5 min to participate in this research. Thanks for cooperating!" The introduction was followed by the items, such as the example given in (2). The list was concluded by a line in which the subject was thanked again.

Table 2

Description of the experiments conducted.

\begin{tabular}{llllcc}
\hline & $\begin{array}{l}\text { Number of } \\
\text { subjects }\end{array}$ & Type(s) of subjects & $\begin{array}{l}\text { Number of } \\
\text { AO items }\end{array}$ & $\begin{array}{l}\text { Number of } \\
\text { production items }\end{array}$ & $\begin{array}{l}\text { Time of } \\
\text { administration (m/yr) }\end{array}$ \\
\hline Experiment 1 & $58^{\text {a }}$ & 1st year students of communication & 5 (out of 13) & 5 & $6 / 2005$ \\
Experiment 2 & 99 & 1st year students of Dutch & 6 (out of 18) & 5 & $10 / 2005$ \\
Experiment 3 & 100 & Students or ex-students & 14 (out of 18) & 14 & $5 / 2007$ \\
Experiment 4 & 100 & Diverse & 8 (out of 14) & 5 & $5 / 2007$ \\
Experiment 5 & 104 & Students Medicine, Psychology, & 2 (out of 7) & 2 & $5 / 2007$ \\
Experiment 6 & 80 & Journalism & 3 (out of 28) & 3 & $7 / 2007$
\end{tabular}

\footnotetext{
${ }^{\mathrm{a}}$ Item non-response hardly occurred in the experiments and reached a maximum of $3 \%$.
} 
A subject always reacted to a mix of positive and negative scenarios-if the first item was positive in version 1 (e.g. 'much time'), the second would probably be negative in that version, and it would be the other way round in version 2 (e.g. 'little time' in the first item). In two sub-versions the order of the answering options was varied to make sure that the positive frame ('my diary is half full') or interpretation was the first answering option for only half of the subjects, and the second answering option for the other half.

\section{Results}

First of all, we need to note that no effects were found for the order of response options. Neither did we find consistent effects of gender or educational background of our subjects $(p>.05)$.

In section 2.1 we proposed two factors expected to affect profiling choices and profile interpretations: Argumentative Orientation (AO) and markedness. In the next section we illustrate how these factors can be demonstrated in a single experimental item.

\subsection{An example}

Consider production item 2 about the diary (see example (2) above, or item 2 in Appendix A.1). The response distribution in Table 3 is arranged in such a way that the expected profile choices are in the first row, and the non-fitting responses in the second. Note however that these expected profiles differ for both conclusions: the little-time conclusion matches the agenda-half-full profile, while for much-time the agenda-half-empty profile is expected to be chosen. AO predicts that matching profiles are chosen more often than non-matching ones. MS predicts that half full will be more frequent in non-matching contexts than half empty will be. In other words, half full will be more often combined with the much-time conclusion than half empty with the little-time conclusion.

By performing a loglinear test on the frequencies in Table 3, both hypotheses can be tested simultaneously. The AOeffect is a so-called one-way effect of matching versus non-matching responses. The MS-effect is a two-way effect of matching on the one hand and the given conclusion on the other hand. Both effects are significant, as indicated by their associated Likelihood Ratio $\mathrm{Chi}^{2}$ values $\left(\mathrm{AO}: \mathrm{Chi}^{2}=27.08\right.$, d.f. $=1, p<.001$; $\mathrm{MS}$ : $\mathrm{Chi}^{2}=9.39$, d.f. $\left.=1, p=.002\right)$.

Let us now inspect the interpretation item constructed for the same scenario (example (3) above, item 1 in Appendix B), for AO-effects and MS-effects.

The response distribution (Table 4) shows that the full-profile was more often continued with the little timeconclusion than the empty-profile. This produces a significant $\mathrm{AO}$-effect $\left(\mathrm{Chi}^{2}=6.06\right.$, d.f. $\left.=1, p=.014\right)$. But again the

Table 3

Results for the diary-production item: frequencies and column totals.

\begin{tabular}{llcl}
\hline Chosen profile & Given conclusion & & \multirow{2}{*}{ Totals } \\
\cline { 2 - 3 } & Little time & Much time & $19(68 \%)$ (half empty) \\
Matching & $29(97 \%)$ (half full) & $9(32 \%)$ (half full) & 48 \\
Non-matching & $1(3 \%)$ (half empty) & 28 & 10 \\
Totals & 30 & & 58 \\
\hline
\end{tabular}

Table 4

Results for the diary interpretation item: frequencies and column totals.

\begin{tabular}{llcc}
\hline Chosen conclusion & Given profile & \\
\cline { 2 - 3 } & Half full diary & Half empty diary & \multirow{2}{*}{ Totals } \\
\hline Matching & $12(25 \%)$ (little time $)$ & $48(100 \%)$ (much time $)$ & 12 \\
Non-matching & $36(75 \%)$ (much time $)$ & $0(0 \%)$ (little time $)$ & 84 \\
Totals & 48 & 48 & 96 \\
\hline
\end{tabular}


markedness asymmetry is present as well: the empty profile could only be coupled to its matching conclusion of much time, while the full profile also allows the non-matching conclusion of much time. In fact, this conclusion is chosen in $75 \%$ of the cases. This MS-effect is significant $\left(\mathrm{Chi}^{2}=73.04\right.$, d.f. $\left.=1, p<.001\right)$.

\subsection{Results for the production items}

We can now discuss the results on a more general level. All our items and their statistics are in Appendices A and B. In the main text, we summarize and discuss the results.

\subsubsection{Argumentative Orientation effects}

Of our 34 production items (see Table 2), 30 displayed significant AO-effects. To appreciate the generality of this result, we need to realize that our items were quite diverse. The 21 full-empty items used a variety of scenarios. In this set, we found 18 significant AO-effects. A binomial test was used to check whether 18 out of 21 hits should in any way be attributed to chance. Clearly, this was not the case $(p<.001)$.

Besides full-empty, we used the following contrast pairs:

- describing the progress of transfer tasks in terms of the contents of the destination (positive frame) or the source container (negative frame),

- describing the progress of a change of state in terms of what has changed already (positive) versus what still has to be done (negative),

- passing or failing exams,

- successful and unsuccessful projects,

- winning or losing matches,

- number of satisfied versus number of dissatisfied customers,

- patient surviving cancer versus dying of cancer,

- number of persons speaking (positive) versus remaining silent (negative) under police questioning.

All these 'other' pairs yielded clear AO-effects. The single exception was item 21 in Appendix A.2, which was later tested on a larger sample (item 22) and then produced a reliable result.

Among the 21 full-empty scenarios were various kinds of concrete and abstract containers and a large variety of conclusion types. Three of these full-empty items did not show AO-effects. A possible cause for this absence is that the focus in these items is more on the process of filling than on the result of that process. We discuss this post hoc explanation a bit further in section 4.2.3.

\subsubsection{Markedness effects}

The analysis for Markedness effects presupposes the identification of marked and unmarked profiles for each item. As explained above, we recognize two factors determining the (un)markedness of profile options. First, there is a general tendency for the positive profile (referring to the presence, rather than the absence of a certain property) to be the unmarked one. Hence full will more often be unmarked than empty. Second, the content of the scenario points to the (un)marked pair member: we hypothesized that the unmarked profile corresponds to the goal, or at least the most preferred outcome of a certain activity. So, for instance:

- the progress of a task is to be measured in terms of how much is already accomplished, not how much should still be done,

- the goal of an exam is passing, not failing; likewise, a tennis match should be won,

- the goal of entertainment activities and lessons is to be attended by an audience; so movie theaters, festival areas, concert halls and classrooms should be full to some degree,

- medical treatments should lead to survival of the patients.

In sum, markedness is affected by both polarity and goal salience. Often, these factors point in the same direction, but sometimes they do not. There are four such exceptions in our 21 full-empty items, which we discuss separately in section 4.2.3.

As explained above, we expected to find Marked Skewness (MS) differences, in which the marked profiles are expected to have a more skewed distribution over fitting and non-fitting conclusion contexts than the unmarked ones. 
First turning to the items with straightforward markedness characteristics, 26 out of the 30 items showed MS-effects ( $p<.001$ in a binomial test). We already illustrated such effects in the Diary example (section 4.1). One of the exceptions was, again, item 21 in Appendix A.2. This item later yielded significant results for MS (as well as AO) when tested again on a larger sample. We return to the three remaining MS-exceptions in section 4.2.3.

\subsubsection{Exceptions in the production items}

Generally, the AO-effects as well as MS-effects in our item set are pervasive. Nevertheless, it is interesting to have a closer look at the exceptions.

In the analysis of AO-effects, three out of 21 items did not show an AO-effect. These three items were similar in that all were about concrete (spatial) containers and in that the scenarios focused on the process of filling itself. (Compare this to the agenda scenario, which is about an abstract container and does not mention the filling process itself, only its result.) There were six filling scenarios of this kind, three of which did show AO-effects, so we need to look closer into these items. The topics were the following:

- a pan that should be filled with peeled potatoes (no AO),

- an iPod that is loading (no AO),

- the fullness of a pool after 20 min of filling with a new filling system (no AO),

- the fullness of a pool after 30 min of filling with a garden hose (AO),

- a new house that is to be filled with furnishings (AO),

- a box with variously shaped holes that is to be filled by putting the matching blocks through the holes (AO).

Why did the first three scenarios items not show an AO-effect, whereas the last three (and all other full-empty) items did? We propose the following (admittedly post hoc) explanation. In the first three filling scenarios, there is a steadily growing mass in the container, with a clear expectation of fullness as the end state. In this type of scenario, the fullness end state is goal salient to such a degree that the unmarked profile can do all the descriptive work by itself, in combination with proportional modifiers.

As an example, consider our potato pan scenario, example (4) (production item 1a in Appendix A.1).

(4) Trudy works as a helper in the kitchen of a restaurant. Saturday morning she had to peel 5 kilos of potatoes. In front of her were a bucket and a pan: the bucket contained the potatoes to be peeled, the pan was to put the peeled potatoes in. The job wasn't as bad as/was worse than she expected.

After 15 minutes the pan was (A) half empty, (B) half full.

In this item, the evaluations made no difference at all: about $80 \%$ of all subjects chose the half full pan. Our explanation is that full is maximally goal salient here: filling the pan is what it is all about, and the saliency of this goal seems to be so strong here that filling it half is still considered a disappointing result. In other words, the unmarked profile, in combination with proportional modifiers, may express both satisfactory and unsatisfactory situations.

The reason that the last three filling items behave differently from the first three seems to be that the expectations differ. In the scenarios about the house and the box, complete fullness is not a real expectation: blocks do not completely fill the space within a box, neither does furniture fill the space within a house. In the two pool-filling items, the difference seems to lie in the level of fullness that is expected. It seems that the new filling system generates higher fullness expectations than the old-fashioned garden hose.

In the markedness analyses, seven items did not show an MS-effect. Four of them were scenarios in which the goal was emptying, whereas full is perceptively salient. A scenario may focus on an entity that is moved elsewhere or consumed, so that the container is being emptied. Hence, in these scenarios goal salience and positivity conflict. For instance, one of the items is about what happens to a cell phone battery during a call. Here, the negative polarity profile (empty) will probably have scenario saliency.

Strikingly, all four scenarios that showed no MS-effect were oriented on emptying (see items 1b, 8, 13, 20). As an example, consider (5) (item 13 in Appendix A.1):

(5) The battery of my cell phone works well/badly. After a call it is (A) half full (B) half empty. 
For (5), negative profiles were about as frequent in the positive conclusion context as were positive profiles in the negative conclusion context (see Appendix A.1). In other words, we found a more or less symmetrical distribution of the profiles, in that they were associated with their matching conclusions to a similar degree.

This at least suggests that MS-effects do not occur when the negative polarity profile is the salient one. When scenario saliency was the sole determiner of (un)markedness, we should have seen a reversed MS-effect in these items, but such a reversal does not occur. It seems that both polarity and scenario salience play a role in markedness assignment, although this of course is a topic for further investigation.

Three other exceptions remain. For two of those, another scenario feature is a possible explanation. In these items (numbers 27 and 33 in Appendix A.2), the participants involved may have different perspectives on the outcome of the event. Although the supermarket wants its customers to be satisfied about the new automatic paying system, the customers might consider it bad news. And not every arrested youth will be willing to speak during police interrogations, since remaining silent might be more in their own interest. So the expected outcome in these scenarios is dependent on the participant, causing the positive profile not to be the unmarked one by definition.

\subsubsection{Conclusions for the production items}

Argumentative Orientation effects are strong and quite general, operating in all kinds of profile contrasts and various kinds of inferences from context to profile.

MS-effects are surprisingly pervasive as well. The complicating factor is that the analysis of these effects presupposes a clear markedness asymmetry in a particular item. Two factors seem important here: polarity (positive profiles tend to be unmarked) and scenario saliency (salient profiles tend to be unmarked). When these two factors conflict, there is no clear markedness asymmetry, and no reliable MS-predictions can be made.

\subsection{Results for the interpretation items}

We presented only four interpretation items (see Appendix B). Our aim was to check whether the bi-directionality for profile effects found by Sher and McKenzie (2006) could be replicated. All four items showed clear AO-effects. This result supports our theoretical explanation of profile effects being derived from a pragmatic heuristic constituted both by speaker and hearer maxims.

In the interpretation items, results for the markedness hypotheses were mixed. Only the diary item (example (3) above) shows a clear MS-effect. One hit out of four tests should be attributed to chance ( $\mathrm{p}=.172)$.

Here, we briefly discuss the exceptions. Interpretation item 2 (see example (10) below), about the concert of a new band, did not show a MS-effect: full elicited interesting-responses to the same degree as empty received boringresponses. This might be due to scenario-specific expectations: perhaps for an entirely new band, a hall half full is already quite satisfactory.

(10) During the concert of a new band, the hall was half full/half empty.

The concert was (A) interesting (B) boring.

Interpretation item 4, which deals with moving stuff out of a former house (see example (11) below), has empty as its scenario salient profile:

(11) Today I'm moving to my new house. In my former house there are still a number of boxes. The hallway there is half full/half empty.

My moving (A) goes swiftly (B) is getting on slow.

Despite its scenario saliency, empty shows a more skewed distribution towards the positive conclusion (81\%-19\%) than full is oriented toward the negative one (full has only $45 \%$ positive conclusions). That is, the tendency for the positive to be unmarked seems to be stronger here than the force of scenario saliency.

The piggy bank item (interpretation item 3, see example (12) below) seems the most complicated one.

(12) I'm saving money for a holiday trip. After six months of saving, the piggy bank is half full/half empty.

(A) My saving project is getting on well, (B) is getting on badly. 
Here full is clearly the unmarked profile in that the scenario is a filling process with fullness as the ultimate goal. However, we found a reversed MS-effect in the sense that half full behaves like the marked profile: it is more skewed in the positive direction than half empty is skewed negatively: half full elicited $75 \%$ positive evaluations while half empty was distributed evenly over positive and negative conclusions $\left(\mathrm{Chi}^{2}=7.77 ; p=.005, \mathrm{Phi}=.28\right)$. Perhaps piggy banks have different fullness standards than other containers, in that half full is rather full already.

\subsubsection{Conclusions for the interpretation items}

For interpretation items, the AO-effects establish beyond any doubt that these orientations have a speaker's and a hearer's side to them.

Marked Skewness should be rejected for the interpretation items, since all four items behave differently in this respect. Possibly the MS effect is stronger in production than in interpretation tasks.

\section{Conclusions and discussion}

In the research presented here, we have demonstrated clear Argumentative Orientation effects in interpretation tasks as well as in production tasks. In our discourse completion tasks, subjects predominantly chose a conclusion that is in line with the direction of the profile, hence inferring the direction of the profile is argumentatively relevant for the conclusion to be drawn; or, conversely, they tend to produce a profile that is compatible with the conclusion supplied. Hence, there is an elegant two-sidedness in interpretation and production that is in line with the linguistic and communicative explanation we propose.

Going beyond the contrasts used in earlier work, we demonstrated the AO-effect in a large variety of lexical contrasts (e.g. full vs. empty, as well as passing vs. failing, or parts of entities or tasks being done vs. still to be done), and a variety of scenarios (including concrete full/empty containers such as bottles, vs. abstract ones such as diaries). Also, the conclusions that were used as contextual determinants were quite varied. Some of them stated that the progress in a task was better or worse than expected, or that there was more or less of a substance in a particular container; the subjects then described the progress in positive or negative terms. These items are still compatible with the reference point notion proposed by Sher and McKenzie (2006). But in other cases inferences were more indirect. For instance, in a number of items the subjects were invited to reason from the evaluations of a movie or concert to the fullness or emptiness of the theater or hall. We do not pretend to have exhausted the types of inferences that are potentially relevant to Argumentative Orientations, but their diversity testifies to the fact that positive or negative Argumentative Orientations are not confined to a small domain of standard inferences. And we may say that the sensitivity of profiles to Argumentative Orientations in the context is a general phenomenon.

The explanation we put forward for these effects is a pragmalinguistic one: the production and interpretation of profiled utterances is guided by a generalized conversational implicature based on what we have called the Argumentative Orientation heuristic. This heuristic basically says that the chosen profile tends to indicate the direction of the conclusion (to be) drawn from the utterance.

Besides Argumentative Orientations, we have shown that in many profiled utterances there is another source of inferences as well: markedness. In a considerable number of cases, an unconventional profile choice yields extra inferences. In particular, the marked profile implicates a stronger Argumentative Orientation than the unmarked profile: the unmarked profile can also be used in the context of an opposite conclusion, whereas this is quite difficult for the marked one.

To our knowledge, this markedness asymmetry is new in the domain of attribute framing research. It is necessary, however, because in addition to Argumentative Orientation, markedness helps to explain why one profile can be preferred over the other. For instance, in cases without any Argumentative Orientation, or with only a weak orientation, (un)markedness is the main determinant of profile choice. And even in cases with clear Argumentative Orientations, a markedness analysis is required to allow for the possibility that the orientation effect is asymmetrical.

Markedness can affect profile interpretation in more ways than was investigated here. It would be interesting to investigate the 'force'-difference further. For instance, the markedness of a profile could very well affect not only the direction of the subsequent conclusion to be drawn, but also the extremity of it. It seems likely that in frame 
interpretation tasks, half empty is compatible with a more extreme negative conclusion than half full is with a positive conclusion (even if the neutral conclusions are removed that follow half full). In frame production, the equivalent would be that a more extreme perception of emptiness is needed to conclude that a glass or concert hall is half empty.

There are a number of other interesting issues for future research. First of all, it is necessary to ask ourselves to what degree discourse completion tasks like the ones we used are comparable to evaluation tasks or behavioral intentions such as reported predominantly in Levin et al. (1998). A distinction should be made between an evaluation attributed to the speaker (as measured in continuation tasks), and whether or not the evaluation is adopted by the listener (as measured in evaluation tasks). Our prediction is that usually the implicated point of view will be adopted in attribute framing experiments, for two reasons: first, because subjects process the text shallowly (heuristically) and therefore tend to go along with the author's frame, and second, as an artifact of the experiment. ${ }^{5}$

Second, besides Argumentative Orientation, Sher and McKenzie have shown other heuristics to be relevant as well. Tests of their Reference Point hypothesis show that inferences about the increasing proportion and about the largest proportion are guiding frame production and frame interpretation too. A particularly interesting topic is how different heuristics may interact in a given discourse context. Our experiments in this article showed that scenarios with a 50/50 proportion have different markedness effects from the experiments with a 40/60 or a 30/70 proportion. In the markedness literature (i.e. Givón, 1995), it is hypothesized that frequency is predictive for perceptual saliency. So, if something occurs relatively often, or is the largest proportion, this is a perceptually (or at least conceptually) salient component of the situation. Hence, it is 'usual' or unmarked to profile this proportion. At the same time, AO requires the profiling of the proportion that is relevant for the conclusion a speaker wants to be drawn, which might also be the smaller proportion. It is a topic for future investigation to see how language users solve this 'conflict' in frame production tasks.

Another line for subsequent research is to elicit different responses to profiling choices instead of, or on top of, discourse continuation tasks. Experiments like the ones reported here can be combined with reading times or reaction times (cf. Sanford et al., 2002). Choosing discourse continuations is a slightly artificial task. Reaction times can be used as additional indicators of the appropriateness of a continuation. Also, surveys offer an excellent task to study profiling choice effects, as they are more of a natural language use situation. In surveys, it is very common to vary the profile of a question in order to avoid 'response sets'. Hence, a question like 'Do you think the government should forbid smoking in public places?' could also be profiled with the verb allow instead of forbid. In a survey task, it could be investigated whether similar attitudes are expressed differently on an agree/disagree-scale due to the use of different profiles in the question (e.g. Holleman, 2006). And a third method to learn more about profiling and markedness is of course to conduct linguistic corpus analyses. For instance, a corpus may be set up to answer a question such as "how large must the component corresponding to the marked profile be in order for the marked profile to become the most frequent choice?'

The production and interpretation of profile choices will continue to provide an interesting meeting point between psychology and linguistic pragmatics.

\section{Acknowledgments}

We thank Bachelor students in 'Communication and Information Studies' Carla Heijms, Teresa Lobosco and Eva Rijk and MA student in 'Communication Studies' Marjolein Kingma, who worked on attribute framing. Our discussions were a contribution to the work we present here, and parts of their data are reported in this article. Furthermore, we thank Carita Paradis, Caroline Willners and Lynne Murphy as well as two anonymous reviewers for their thoughtful comments on earlier versions of this article. They substantially contributed to improved versions of our manuscript.

\footnotetext{
${ }^{5}$ Recently, however, Igou and Bless (2006) have challenged the idea that framing effects are due to heuristic processing styles. Their research on risky choice framing suggests that more elaborate 'constructive' processing adds to framing effects. See also Schwarz (1996) on the ways in which the design of (risky choice) framing experiments biases subjects' judgements.
} 


\section{Appendix A. Items and statistical information}

\section{Legend}

- $\mathrm{AO}=$ argumentative orientation effect $(1-$ way effect of row, d.f. $=1$ )

- MS = marked skewness effect $(2$-way effect of column vs. row, d.f. $=1)$

- * $\quad=$ one-tailed $p$ value

- italics $=$ text that differs between conditions

- (A), (B) = options presented to the subjects

- $\mathrm{PC} / \mathrm{NC}=$ positive/negative conclusion (= conclusion corresponding to positive/negative profile)

- $\mathrm{MP} / \mathrm{NMP}=$ matching/non-matching profile $($ matching $=$ corresponding to direction of the conclusion)

\section{A.1. Production items 1 - full/empty scenarios}

\begin{tabular}{|c|c|c|}
\hline Nr. & Exp. & Item \\
\hline 1a & 2 & $\begin{array}{l}\text { Trudy works as a helper in the kitchen of a restaurant. } \\
\text { Saturday morning she had had to peel } 5 \text { kilos of potatoes. } \\
\text { In front of her were a bucket and a pan: the bucket } \\
\text { contained the potatoes to be peeled, the pan was to put the } \\
\text { peeled potatoes in. The job wasn't as bad as/was worse } \\
\text { than she expected. }\end{array}$ \\
\hline
\end{tabular}

1b 2 (Context identical to item 1) After 15 minutes the bucket was (A) half empty (B) half full.

$2 \quad 1 \quad$ Next week I'll have much/little time to come over and help you with odd jobs about the house. My diary is (A) half full (B) half empty.

34 The new movie is a huge success/a total flop. When it began, the movie theater was (A) half full (B) half empty

44 Few/Many high school pupils skip classes. As a result few/many lessons are missed. During the Dutch lessons the classroom is (A) half full (B) half empty.

54 My iPod has been repaired/does not work well and now it is loading fast/slowly. After some minutes of charging it is (A) half full (B) half empty

64 Yesterday I had my birthday party and/but I got a lot of/ only a few presents. At the end of the day, the table for my presents was (A) half full (B) half empty.

The Freedom Festival in Zwolle was a/not $a$ success. The festival area was (A) half full (B) half empty.

When I started cooking I found out that there was less/more frying oil than I had expected. The bottle was (A) half full (B) half empty.

The last few years I have bought many new clothes/only few new clothes. My wardrobe is (A) half full (B) half empty.

Moving our stuff into the new house is going well/is progressing slowly. At night, the house is (A) half full (B) half empty.

For the one-year-old girl it seems easy/difficult to put the blocks in the correct holes of the box. At the end of the afternoon, the box is (A) half full (B) half empty.

\begin{tabular}{lllll}
\multicolumn{2}{l}{ Frequencies } & & $\mathrm{AO}$ & $\mathrm{MS}$ \\
$\mathrm{MP}$ & $\mathrm{PC}$ & $\mathrm{NC}$ & n.s. & $\mathrm{Chi}^{2}=18.32$ \\
$\mathrm{NM}$ & 5 & 5 & & $p<.001$ \\
& 5 & 19 & &
\end{tabular}

\begin{tabular}{|c|c|c|c|c|}
\hline & $\mathrm{PC}$ & $\mathrm{NC}$ & & n.s. \\
\hline MP & 19 & 19 & $p<.001$ & \\
\hline NMP & 6 & 6 & & \\
\hline $\begin{array}{l}\text { MP } \\
\text { NM }\end{array}$ & $\begin{array}{l}\text { PC } \\
19 \\
9\end{array}$ & $\begin{array}{l}\text { NC } \\
29 \\
1\end{array}$ & $\begin{array}{l}\mathrm{Chi}^{2}=27.08 \\
p<.001\end{array}$ & $\begin{array}{l}\mathrm{Chi}^{2}=9.39 \\
p=.002\end{array}$ \\
\hline $\begin{array}{l}\text { MP } \\
\text { NMP }\end{array}$ & $\begin{array}{l}\mathrm{PC} \\
45 \\
5\end{array}$ & $\begin{array}{l}\text { NC } \\
21 \\
29\end{array}$ & $\begin{array}{l}\mathrm{Chi}^{2}=10.42 \\
p=.005\end{array}$ & $\begin{array}{l}\mathrm{Chi}^{2}=27.67 \\
p<.001\end{array}$ \\
\hline $\begin{array}{l}\text { MP } \\
\text { NMP }\end{array}$ & $\begin{array}{l}\text { PC } \\
41 \\
9\end{array}$ & $\begin{array}{l}\mathrm{NC} \\
35 \\
15\end{array}$ & $\begin{array}{l}\mathrm{Chi}^{2}=28.41 \\
p<.001\end{array}$ & n.s. \\
\hline $\begin{array}{l}\text { MP } \\
\text { NMP }\end{array}$ & $\begin{array}{l}\mathrm{PC} \\
47 \\
3\end{array}$ & $\begin{array}{l}\text { NC } \\
10 \\
40\end{array}$ & n.s. & $\begin{array}{l}\mathrm{Chi}^{2}=63.93 \\
p<.001\end{array}$ \\
\hline $\begin{array}{l}\text { MP } \\
\text { NMP }\end{array}$ & $\begin{array}{l}\mathrm{PC} \\
50 \\
0\end{array}$ & $\begin{array}{l}\text { NC } \\
20 \\
30\end{array}$ & $\begin{array}{l}\mathrm{Chi}^{2}=16.21 \\
p<.001\end{array}$ & $\begin{array}{l}\mathrm{Chi}^{2}=50.94 \\
p<.001\end{array}$ \\
\hline $\begin{array}{l}\text { MP } \\
\text { NMP }\end{array}$ & $\begin{array}{l}\mathrm{PC} \\
48 \\
2\end{array}$ & $\begin{array}{l}\mathrm{NC} \\
37 \\
13\end{array}$ & $\begin{array}{l}\mathrm{Chi}^{2}=54.09 \\
p<.001\end{array}$ & $\begin{array}{l}\mathrm{Chi}^{2}=10.44 \\
p=.001\end{array}$ \\
\hline $\begin{array}{l}\text { MP } \\
\text { NMP }\end{array}$ & $\begin{array}{l}\text { PC } \\
39 \\
11\end{array}$ & $\begin{array}{l}\mathrm{NC} \\
36 \\
14\end{array}$ & $\begin{array}{l}\mathrm{Chi}^{2}=26.16 \\
p<.001\end{array}$ & n.s. \\
\hline $\begin{array}{l}\text { MP } \\
\text { NMP }\end{array}$ & $\begin{array}{l}\mathrm{PC} \\
48 \\
2\end{array}$ & $\begin{array}{l}\mathrm{NC} \\
37 \\
13\end{array}$ & $\begin{array}{l}\mathrm{Chi}^{2}=54.09 \\
p<.001\end{array}$ & $\begin{array}{l}\mathrm{Chi}^{2}=10.44 \\
p=.001\end{array}$ \\
\hline $\begin{array}{l}\text { MP } \\
\text { NMP }\end{array}$ & $\begin{array}{l}\mathrm{PC} \\
49 \\
1\end{array}$ & $\begin{array}{l}\text { NC } \\
24 \\
26\end{array}$ & $\begin{array}{l}\mathrm{Chi}^{2}=21.98 \\
p<.001\end{array}$ & $\begin{array}{l}\mathrm{Chi}^{2}=37.61 \\
p<.001\end{array}$ \\
\hline MP & $\begin{array}{l}\mathrm{PC} \\
48\end{array}$ & $\begin{array}{l}\mathrm{NC} \\
16\end{array}$ & $\begin{array}{l}\mathrm{Chi}^{2}=7.95 \\
p=.005\end{array}$ & $\begin{array}{l}\mathrm{Chi}^{2}=51.20 \\
p<.001\end{array}$ \\
\hline
\end{tabular}


A.1 (Continued)

\begin{tabular}{|c|c|c|c|c|c|c|c|}
\hline Nr. & Exp. & Item & Frequ & & & $\mathrm{AO}$ & MS \\
\hline 12 & 4 & $\begin{array}{l}\text { During a night's work at the restaurant we got many/few } \\
\text { tips. The tip bowl was (A) half full (B) half empty. }\end{array}$ & $\begin{array}{l}\text { MP } \\
\text { NMP }\end{array}$ & $\begin{array}{l}\mathrm{PC} \\
49 \\
1\end{array}$ & $\begin{array}{l}\text { NC } \\
25 \\
25\end{array}$ & $\begin{array}{l}\mathrm{Chi}^{2}=24.02 \\
p<.001\end{array}$ & $\begin{array}{l}\mathrm{Chi}^{2}=35.49 \\
p<.001\end{array}$ \\
\hline 13 & 4 & $\begin{array}{l}\text { The battery of my cell phone works well/badly. After a } \\
\text { call, it is (A) half full (B) half empty. }\end{array}$ & $\begin{array}{l}\text { MP } \\
\text { NMP }\end{array}$ & $\begin{array}{l}\text { PC } \\
34 \\
16\end{array}$ & $\begin{array}{l}\mathrm{NC} \\
40 \\
10\end{array}$ & $\begin{array}{l}\mathrm{Chi}^{2}=24.02 \\
p<.001\end{array}$ & n.s. \\
\hline 14 & 4 & $\begin{array}{l}\text { I will/will not go shopping today, because there are lots of } \\
\text { supplies/almost no supplies at home. The storage } \\
\text { cupboard is (A) half full (B) half empty. }\end{array}$ & $\begin{array}{l}\text { MP } \\
\text { NMP }\end{array}$ & $\begin{array}{l}\mathrm{PC} \\
48 \\
2\end{array}$ & $\begin{array}{l}\mathrm{NC} \\
41 \\
9\end{array}$ & $\begin{array}{l}\mathrm{Chi}^{2}=69.33 \\
p<.001\end{array}$ & $\begin{array}{l}\mathrm{Chi}^{2}=5.37 \\
p=.020\end{array}$ \\
\hline 15 & 4 & $\begin{array}{l}\text { With this new system, the pool can be filled fast/only } \\
\text { slowly. After } 20 \text { minutes, it is (A) half full (B) half empty. }\end{array}$ & $\begin{array}{l}\text { MP } \\
\text { NMP }\end{array}$ & $\begin{array}{l}\text { PC } \\
50 \\
0\end{array}$ & $\begin{array}{l}\mathrm{NC} \\
6 \\
44\end{array}$ & n.s. & $\begin{array}{l}\mathrm{Chi}^{2}=100.49 \\
p<.001\end{array}$ \\
\hline 16 & 4 & $\begin{array}{l}\text { The new amusement park attracts many/only few people. } \\
\text { Its attractions are all (A) half full (B) half empty. }\end{array}$ & $\begin{array}{l}\text { MP } \\
\text { NMP }\end{array}$ & $\begin{array}{l}\mathrm{PC} \\
49 \\
1\end{array}$ & $\begin{array}{l}\text { NC } \\
29 \\
21\end{array}$ & $\begin{array}{l}\mathrm{Chi}^{2}=33.25 \\
p<.001\end{array}$ & $\begin{array}{l}\mathrm{Chi}^{2}=27.55 \\
p<.001\end{array}$ \\
\hline 17 & 3 & $\begin{array}{l}\text { Sunday is my washing day. This week, I have more/less } \\
\text { laundry than usual. When I look into the clothes basket, it } \\
\text { is (A) half full (B) half empty. }\end{array}$ & $\begin{array}{l}\text { MP } \\
\text { NMP }\end{array}$ & $\begin{array}{l}\text { PC } \\
43 \\
9\end{array}$ & $\begin{array}{l}\mathrm{NC} \\
16 \\
32\end{array}$ & $\begin{array}{l}\mathrm{Chi}^{2}=3.26 \\
p=.036^{*}\end{array}$ & $\begin{array}{l}\mathrm{Chi}^{2}=26.35 \\
p<.001\end{array}$ \\
\hline 18 & 3 & $\begin{array}{l}\text { During a concert that has got a good/bad review, the hall } \\
\text { is (A) half full (B) half empty. }\end{array}$ & $\begin{array}{l}\text { MP } \\
\text { NMP }\end{array}$ & $\begin{array}{l}\mathrm{PC} \\
40 \\
8\end{array}$ & $\begin{array}{l}\text { NC } \\
31 \\
21\end{array}$ & $\begin{array}{l}\mathrm{Chi}^{2}=18.20 \\
p<.001\end{array}$ & $\begin{array}{l}\mathrm{Chi}^{2}=7.02 \\
p<.01\end{array}$ \\
\hline 19 & 3 & $\begin{array}{l}\text { On a warm summer's day, I decide to fill the pool. With } \\
\text { the garden hose this goes fast/slowly. After half an hour, } \\
\text { the pool is (A) half full (B) half empty. }\end{array}$ & $\begin{array}{l}\text { MP } \\
\text { NMP }\end{array}$ & $\begin{array}{l}\mathrm{PC} \\
44 \\
4\end{array}$ & $\begin{array}{l}\mathrm{NC} \\
17 \\
35\end{array}$ & $\begin{array}{l}\mathrm{Chi}^{2}=4.88 \\
p=.027\end{array}$ & $\begin{array}{l}\mathrm{Chi}^{2}=40.49 \\
p<.001\end{array}$ \\
\hline 20 & 3 & $\begin{array}{l}\text { During a party I was served a good/bad wine. After } \\
\text { several sips my glass was half full/half empty. }\end{array}$ & $\begin{array}{l}\text { MP } \\
\text { NMP }\end{array}$ & $\begin{array}{l}\mathrm{PC} \\
32 \\
20\end{array}$ & $\begin{array}{l}\mathrm{NC} \\
32 \\
16\end{array}$ & $\begin{array}{l}\mathrm{Chi}^{2}=7.95 \\
p=.005\end{array}$ & n.s. \\
\hline
\end{tabular}

\section{A.2. Production items 2 - other contrasts}

\begin{tabular}{|c|c|c|c|c|c|c|c|}
\hline Nr. & Exp. & Item & & & & $\mathrm{AO}$ & MS \\
\hline 21 & 1 & $\begin{array}{l}\text { Carel is moving to another house. He has to load } 36 \text { boxes from his living } \\
\text { room into the moving van. After a while the work is progressing faster/slower } \\
\text { than expected. There are } 18 \text { boxes in the (A) moving van (B) living room }\end{array}$ & $\begin{array}{l}\text { MP } \\
\text { NMP }\end{array}$ & $\begin{array}{l}\mathrm{PC} \\
19 \\
9\end{array}$ & $\begin{array}{l}\mathrm{NC} \\
15 \\
15\end{array}$ & n.s. & n.s. \\
\hline 22 & 2 & $\begin{array}{l}\text { Carel is moving to another house. He has to load } 36 \text { boxes from his living } \\
\text { room into the moving van. After a while the work is progressing faster/slower } \\
\text { than expected. There are } 18 \text { boxes in the (A) moving van (B) living room }\end{array}$ & $\begin{array}{l}\text { MP } \\
\text { NMP }\end{array}$ & $\begin{array}{l}\mathrm{PC} \\
39 \\
10\end{array}$ & $\begin{array}{l}\mathrm{NC} \\
18 \\
31\end{array}$ & $\begin{array}{l}\mathrm{Chi}^{2}=18.60 \\
p<.001\end{array}$ & $\begin{array}{l}\mathrm{Chi}^{2}=3.23 \\
p=.036^{*}\end{array}$ \\
\hline 23 & 1 & $\begin{array}{l}\text { The quality of the driving lessons in The Netherlands is going up. At the } \\
\text { moment, (1) } 60 \% \text { of the driving school clients pass the first driving exam, as } \\
\text { against } 50 \% \text { four years ago/(2) } 40 \% \text { of the driving school clients fail the first }\end{array}$ & $\begin{array}{l}\text { MP } \\
\text { NMP }\end{array}$ & $\begin{array}{l}\mathrm{PC} \\
29 \\
1\end{array}$ & $\begin{array}{l}\text { NC } \\
19 \\
9\end{array}$ & $\begin{array}{l}\mathrm{Chi}^{2}=27.08 \\
p<.001\end{array}$ & $\begin{array}{l}\mathrm{Chi}^{2}=9.39 \\
p=.002\end{array}$ \\
\hline
\end{tabular}
driving exam, as against $50 \%$ four years ago. (A) 1 sounds more natural than 2 (B) 2 sounds more natural than 1

The quality of the driving lessons is going down lately. At the moment, (1) $50 \%$ of the driving school clients pass the first driving exam, as against $60 \%$ four years ago/(2) $50 \%$ of the driving school clients fail the first driving exam, as against $40 \%$ four years ago (A) 1 sounds more natural than 2 (B) 2 sounds more natural than 1

241 Prospective employees in the security sector are now required to do a theory exam. The exam is rather easy/rather difficult for them.

(A) The passing rate is about $60 \%$.
(B) The failure rate is about $40 \%$.

$\begin{array}{lllll} & \text { PC } & \text { NC } & \mathrm{Chi}^{2}=56.79 & \mathrm{Chi}^{2}=4.55 \\ \text { MP } & 30 & 25 & p<.001 & p=.033 \\ \text { NMP } & 0 & 3 & & \end{array}$


A.2 (Continued)

\begin{tabular}{|c|c|c|c|c|c|c|c|}
\hline $\mathrm{Nr}$. & Exp. & Item & & & & $\mathrm{AO}$ & MS \\
\hline 25 & 2 & $\begin{array}{l}\text { Prospective employees in the security sector are now required to do a theory } \\
\text { exam. The exam is rather easy/rather difficult for them. } \\
\text { (A) } 60 \% \text { pass the exam the first time they do it. } \\
\text { (B) } 40 \% \text { fail the exam the first time they do it. }\end{array}$ & $\begin{array}{l}\text { MP } \\
\text { NMP }\end{array}$ & $\begin{array}{l}\mathrm{PC} \\
44 \\
4\end{array}$ & $\begin{array}{l}\mathrm{NC} \\
14 \\
34\end{array}$ & $\begin{array}{l}\mathrm{Chi}^{2}=4.20 \\
p=.04\end{array}$ & $\begin{array}{l}\mathrm{Chi}^{2}=43.40 \\
p<.001\end{array}$ \\
\hline 26 & 2 & $\begin{array}{l}\text { For tennis pro Melle van Gemerden, } 2005 \text { was a good/bad year. He (A) won } 2 \\
\text { (B) lost } 5 \text { out of his } 7 \text { international tournament matches. }\end{array}$ & $\begin{array}{l}\text { MP } \\
\text { NMP }\end{array}$ & $\begin{array}{l}\mathrm{PC} \\
30 \\
0\end{array}$ & $\begin{array}{l}\mathrm{NC} \\
25 \\
3\end{array}$ & $\begin{array}{l}\mathrm{Chi}^{2}=56.79 \\
p<.001\end{array}$ & $\begin{array}{l}\mathrm{Chi}^{2}=4.55 \\
p=.033\end{array}$ \\
\hline 27 & 2 & $\begin{array}{l}\text { As of January 1st, the supermarket introduced a new automatic paying system. } \\
\text { POS1: As a result, the waiting times at the check-out have gone down. } \\
\text { POS2: As a result, the flow rate of customers at the check-out has gone up. }\end{array}$ & $\begin{array}{l}\text { MP } \\
\text { NMP }\end{array}$ & $\begin{array}{l}\mathrm{PC} \\
31 \\
18\end{array}$ & $\begin{array}{l}\text { NC } \\
29 \\
20\end{array}$ & $\begin{array}{l}\mathrm{Chi}^{2}=4.98 \\
p=.026\end{array}$ & n.s. \\
\hline
\end{tabular}

NEG1: As a result, the waiting times at the check-out have gone down.

NEG2: As a result, the flow rate of customers at the check-out has gone up.

Positive options: (A) The number of satisfied customers has increased.

(B) The number of dissatisfied customers has decreased.

Negative options: (A) The number of satisfied customers has decreased.

(B) The number of dissatisfied customers has increased.

283 During an easy/a difficult exam, (A) the pass rate is $70 \%$ (B) the failure rate is $30 \%$.

295 The creative innovation team of the Talpa TV Company has to come up with new ideas all the time. Out of the last 10 ideas that have led to new shows, 3 have been a success and 7 have failed. The team has a good/bad record. ... out of 10 ideas have (A) been a success (B) failed.

305 In the United States, a new cancer therapy has been introduced. Half of the patients undergoing this experimental treatment survive, the other half die. The governmental authorities have reacted positively/negatively to the new therapy. ...\% of the patients undergoing this treatment are going to (A) survive (B) die.

316 Lisa is washing her car. The work is going wellis progressing slowly. After an hour, half of the car is (A) clean (B) dirty.

326 John is mowing his garden lawn. The work is going well/is progressing slowly. After half an hour, (A) he has mown half of the lawn (B) he has still to do half of the lawn.

336 During riots in the center of town last Saturday, 20 youths were arrested. They were interviewed by the police the same evening. The officers had no trouble/ had a hard time collecting information. Ten of the youths (A) spoke (B) remained silent during the examination.

$\begin{array}{lllll} & \mathrm{PC} & \mathrm{NC} & \mathrm{Chi}^{2}=10.42 & \mathrm{Chi}^{2}=29.82 \\ \text { MP } & 44 & 22 & p=.001 & p<.001 \\ \text { NMP } & 4 & 30 & & \\ & \text { PC } & \text { NC } & \mathrm{Chi}^{2}=3.87 & \mathrm{Chi}^{2}=7.95 \\ \text { MP } & 28 & 14 & p=.049 & p=.005 \\ \text { NMP } & 24 & 38 & & \\ & & & & \\ & \text { PC } & \text { NC } & \mathrm{Chi}^{2}=14.21 & \mathrm{Chi}^{2}=25.26 \\ \text { MP } & 47 & 24 & p<.001 & p<.001 \\ \text { NMP } & 5 & 28 & & \\ & & & & \\ & & & & \\ & \text { PC } & \text { NC } & \mathrm{Chi}^{2}=11.53 & \mathrm{Chi}^{2}=23.01 \\ \text { MP } & 37 & 18 & p=.001 & p<.001 \\ \text { NMP } & 3 & 22 & & \\ & \text { PC } & \text { NC } & \mathrm{Chi}^{2}=11.53 & \mathrm{Chi}^{2}=13.78 \\ \text { MP } & 35 & 20 & p=.001 & p<.001 \\ \text { NMP } & 5 & 20 & & \\ & \text { PC } & \text { NC } & \mathrm{Chi}^{2}=20.93 & \text { n.s. } \\ \text { MP } & 29 & 31 & p<.001 & \\ \text { NMP } & 11 & 9 & & \\ & & & & \end{array}$

\section{Appendix B. Interpretation items}

\section{Legend}

- $\mathrm{PP} / \mathrm{NP} \quad=$ positive/negative profile

- $\mathrm{MC} / \mathrm{NMC}=$ matching/non-matching conclusion $($ matching $=$ corresponding to direction of the profile)

\begin{tabular}{|c|c|c|c|c|c|c|c|}
\hline Nr. & Exp. & Item & & & & $\mathrm{AO}$ & MS \\
\hline 1 & 2 & $\begin{array}{l}\text { My diary is half full/half empty. } \\
\text { Next week I'll have (A) much time (B) little time to come } \\
\text { over and help you with odd jobs about the house. }\end{array}$ & $\begin{array}{l}\text { MC } \\
\text { NMC }\end{array}$ & $\begin{array}{l}\text { PP } \\
12 \\
36\end{array}$ & $\begin{array}{l}\text { NP } \\
48 \\
0\end{array}$ & $\begin{array}{l}\mathrm{Chi}^{2}=6.06 \\
p=.014\end{array}$ & $\begin{array}{l}\mathrm{Chi}^{2}=73.04 \\
p<.001\end{array}$ \\
\hline 2 & 3 & $\begin{array}{l}\text { During the concert of a new band, the hall was half full } \\
\text { half empty. } \\
\text { The concert was (A) interesting (B) boring. }\end{array}$ & $\begin{array}{l}\text { MC } \\
\text { NMC }\end{array}$ & $\begin{array}{l}\text { PP } \\
35 \\
13\end{array}$ & $\begin{array}{l}\text { NP } \\
33 \\
19\end{array}$ & $\begin{array}{l}\mathrm{Chi}^{2}=13.26 \\
p<.001\end{array}$ & n.s. \\
\hline
\end{tabular}


Appendix B (Continued)

\begin{tabular}{|c|c|c|c|c|c|c|c|}
\hline $\mathrm{Nr}$. & Exp. & Item & & & & $\mathrm{AO}$ & MS \\
\hline 3 & 3 & $\begin{array}{l}\text { I'm saving money for a holiday trip. After six months of } \\
\text { saving, the piggy bank is half full/half empty. } \\
\text { (A) My saving project is going well/(B) is going badly. }\end{array}$ & $\begin{array}{l}\mathrm{MC} \\
\mathrm{NMC}\end{array}$ & $\begin{array}{l}\text { PP } \\
39 \\
13\end{array}$ & $\begin{array}{l}\text { NP } \\
23 \\
25\end{array}$ & $\begin{array}{l}\mathrm{Chi}^{2}=5.82 \\
p=.016\end{array}$ & $\begin{array}{l}\text { Full is more skewed: } \\
\mathrm{Chi}^{2}=7.87 \\
p=.005\end{array}$ \\
\hline 4 & 3 & $\begin{array}{l}\text { Today I'm moving to my new house. In my former house } \\
\text { there are still a number of boxes. The hallway there is } \\
\text { half full/half empty. My moving (A) is going swiftly/(B) } \\
\text { is going slowly. }\end{array}$ & $\begin{array}{l}\mathrm{MC} \\
\mathrm{NMC}\end{array}$ & $\begin{array}{l}\text { PP } \\
23 \\
29\end{array}$ & $\begin{array}{l}\text { NP } \\
39 \\
9\end{array}$ & $\begin{array}{l}\mathrm{Chi}^{2}=5.82 \\
p=.016\end{array}$ & $\begin{array}{l}\mathrm{Chi}^{2}=15.09 \\
p<.001\end{array}$ \\
\hline
\end{tabular}

\section{References}

Bultinck, Bert, 2005. Numerous Meanings: The Meaning of English Cardinals and the Legacy of Paul Grice. Elsevier, London.

Comrie, Bernard, 1996. Markedness. In: Verschueren, J., Östman, J.-O., Blommaert, J., Bulcaen, C. (Eds.), Handbook of Pragmatics. John Benjamins, Amsterdam/Philadelphia, pp. 1-13.

Croft, William, Cruse, D.A., 2004. Cognitive Linguistics. Cambridge University Press, Cambridge.

Ducrot, Oswald, 1973. La prevue et le dire. Maison Mame, Paris.

Ducrot, Oswald, 1980. Les échelles argumentatives. Les Editions de Minuit, Paris.

Givón, T., 1995. Functionalism and grammar. John Benjamins, Amsterdam.

Haspelmath, Martin, 2006. Against markedness (and what to replace it with). Journal of Linguistics 42, 25-70.

Holleman, Bregje C., 2006. The meanings of 'yes' and 'no': an explanation for the forbid/allow asymmetry. Quality \& Quantity 40, 10-38.

Horn, Laurence R., 1989. A Natural History of Negation. University of Chicago Press, Chicago.

Igou, Eric R., Bless, Herbert, 2006. On undesirable consequences of thinking: framing effects as a function of substantive processing. Journal of Behavioral Decision Making 20, 125-142.

Kennedy, Christopher, McNally, Louise, 2005. Scale structure, degree modification, and the semantics of gradable predicates. Language 81, 345381.

Langacker, Ron A., 2000. Why a mind is necessary. Conceptualisation, grammar and linguistic semantics. In: Albertazzi, L. (Ed.), Meaning and Cognition. John Benjamins, Amsterdam, pp. 25-38.

Levin, Irwin P., Gaeth, Gary J., 1988. Framing of attribute information before and after consuming the product. Journal of Consumer Research 15 , 374-378.

Levin, Irwin P., Gaeth, Gary J., Schreiber, Judy, Lauriola, Marco, 2002. A new look at framing effects: distribution of effect sizes, individual differences, and independence of types of effects. Organizational Behavior and Human Decision Processes 88 (1), $411-429$.

Levin, Irwin P., Schneider, Sandra L., Gaeth, Gary J., 1998. All frames are not created equal: a typology and critical analysis of framing effects. Organizational Behavior and Human Decision Processes 76, 149-188.

Levinson, Stephen C., 2000. Presumptive Meanings: The Theory of Generalized Conversational Implicature. MIT Press, Cambridge, MA.

Murphy, M. Lynne, 2003. Semantic Relations and the Lexicon: Antonymy, Synonymy, and Other Paradigms. Cambridge University Press, Cambridge.

Pander Maat, Henk L.W., 2006. Subjectification in gradable adjectives. In: Athanasiadou, A., Canakis, C., Cornillie, B. (Eds.), Subjectification: Various Paths to Subjectivity. Mouton de Gruyter, Berlin/New York, pp. 279-320.

Paradis, Carita, Willners, Caroline, 2005. Antonymy and negation-the boundedness hypothesis. Journal of Pragmatics 38, 1051-1080.

Petty, Richard E., Cacioppo, John T., 1986. Communication and Persuasion: Central and Peripheral Routes to Attitude Change. Springer, New York.

Sanford, Anthony J., Fay, Nicolas, Stewart, Andrew, Moxey, Linda, 2002. Perspective in statements of quantity, with implications for consumer psychology. Psychological Science 13, 130-134.

Schwarz, Norbert, 1996. Cognition and Communication: Judgmental Biases, Research Methods and the Logic of Conversation. Lawrence Erlbaum Associates, New Jersey.

Sher, Schlomi, McKenzie, Craig R.M., 2006. Information leakage from logically equivalent frames. Cognition 101, 467-494.

Teigen, Karl H., Karevold, Knut I., 2005. Looking back versus looking ahead: framing of time and work at different stages of the project. Journal of Behavioral Decision Making 18, 229-246.

Tversky, Amos, Kahneman, Daniel, 1981. The framing of decisions and the psychology of choice. Science 211, 453-458.

Bregje Holleman is an assistant professor at the Department of Dutch and the Utrecht Institute of Linguistics OTS at Utrecht University. Her research and teaching focuses on language use and cognitive processes of text interpretation. Her main research interests are how question wording in attitude surveys affects the answers, and framing effects.

Henk Pander Maat is an associate professor at the Department of Dutch and the Utrecht Institute of Linguistics OTS at Utrecht University. At the moment his research and teaching focuses on discourse coherence, readability and text comprehension and framing effects. 